\title{
Health Literacy Instrument in Family Medicine: The "Newest Vital Sign" Ease of Use and Correlates
}

\author{
Lisa Ciccarelli Shah, DO, Patricia West, PhD, Katazryna Bremmeyr, MD, and \\ Ruth T. Savoy-Moore, PhD
}

Background: Health literacy has been defined as the ability to obtain, process, and understand the basic information needed to make appropriate health decisions. Half of adults lack the health literacy skills needed for our complex health care environment. In 2005, Weiss et al introduced the Newest Vital Sign (NVS), an instrument that can be used to quickly assess health literacy. The purpose of this study was to determine the acceptability and timeliness of using the NVS to measure the level of health literacy in various suburban, urban, and rural primary care settings. A secondary purpose was to determine the influence of taking a health class on one's level of health literacy.

Methods: In this cross-sectional design, adults were recruited from 4 primary care settings and student athletes were recruited during preparticipation sports physicals. The NVS was administered and health literacy rates were compared with known trends. A subset of $\mathbf{5 0}$ patients was timed during test administration, and refusals were logged throughout. The adults and the athletes were analyzed separately.

Results: One thousand fourteen patients (including athletes) agreed to participate (response rate, 97.5\%). Average time needed to complete the NVS was 2.63 minutes. Of the adults tested, $48.1 \%$ demonstrated adequate health literacy. In logistic regression analysis, younger age, more formal education, health class participation, and body mass index were positive predictors of adequate health literacy among adults. An interaction term was used for gender/race, with white women used as the comparator. The gender/race odds ratio negatively affected literacy, with white men at 0.497 (95\% CI, 0.328-0.753), non-white women at 0.177 (95\% CI, 0.111-0.282), and non-white men at 0.210 (95\% CI, 0.110-0.398). Among the participating middle- and high-school athletes, $59.7 \%$ had adequate health literacy. In logistic regression of this population, body mass index was a positive predictor whereas gender/race was a negative predictor.

Conclusion: The NVS revealed health literacy status in less than 3 minutes, was widely accepted, and provided results comparable to more extensive literacy tests. Particularly, taking a health education class was associated with higher levels of health literacy among adults. (J Am Board Fam Med 2010;23:195-203.)

Keywords: Health Literacy, Newest Vital Sign, NVS

Health literacy has been defined as the ability to obtain, process, and understand basic information

This article was externally peer reviewed.

Submitted 17 December 2007; revised 15 August 2009; accepted 21 August 2009.

From the Department of Family Medicine, St. John Hospital, Detroit, MI.

Funding: Funding was provided by the St. John Hospital Departments of Graduate Medical Education and Biomedical Investigation, Detroit, MI.

Prior presentation: Poster presentation during the American Academy of Family Physicians Scientific Assembly, Chicago, Illinois (October 2007); oral presentation during the 30th Annual Michigan Family Medicine Research Day Conference, Brighton, Michigan (May 2007); and poster presentation during the Society of Teachers of Family Medicine Annual Spring Conference, Chicago, Illinois (May 2007).

Conflict of interest: none declared.

Corresponding author: Lisa Ciccarelli Shah, DO, 241 Charles Dimock Parkway, Suite \#6, Colonial Heights, VA 23834 (E-mail: 1shahpcfp@gmail.com). and services needed to make appropriate health decisions. ${ }^{1}$ A patient must be able to understand and use information in a meaningful way to be able to improve health and nutrition. Furthermore, education level, reading level, and other demographics alone do not accurately predict a patient's health literacy. The average, English-speaking US adult reads at an 8th- to 9th-grade level whereas most health care materials are written at 10th-grade level or higher. ${ }^{2-4}$

Everyday in a physician's office, patients are asked to sign forms consenting to treatment, stating specifics regarding a procedure, or detailing privacy of medical records and transference of medical records. They are also given written and verbal information about their medical condition(s) and/or prevention of disease. To have appropriate 
educational materials and standardized forms available that foster a fully informed decision regarding a patient's health care needs and rights, a physician must know the average health literacy level of his or her patient population. Physicians often have difficulty recognizing individuals with poor literacy skills $^{5,6}$ and overestimate patients' levels of health literacy, especially among minorities. ${ }^{7}$

The Joint Commission on Accreditation of Health Care Organizations established health literacy benchmarks for hospitals to achieve by $2010 .^{2}$ In 2004, the Institutes of Medicine, the Agency for Healthcare Research and Quality, and the American Medical Association all issued reports about health literacy, ${ }^{1}$ noting that up to $50 \%$ of adults lack the literacy skills needed to function adequately in a health care environment. Inadequate health literacy has been associated with increased incidence of smoking, advanced age, increased risk of hospitalizations, increased likelihood of carrying a weapon, higher glycated hemoglobin levels, and a decreased incidence of breastfeeding. ${ }^{4,8-12}$ However, other investigators found mixed results when they examined the association between the level of health literacy and health outcomes. ${ }^{13,14}$

Efforts have been made to improve the level of health literacy among health care recipients as well as among the general public. Health care providers have modified educational materials or have used visual or multimodal teaching techniques. Mandatory health education classes have become more prevalent in middle and high schools, although their impact on improving health literacy is unclear. ${ }^{15}$

The Test of Functional Health Literacy in Adults (TOFHLA) has been widely used for assessing health literacy, but takes 18 to 22 minutes to administer. The short form (S-TOFHLA) can take 7 to 10 minutes to administer. In 2005, Weiss et $\mathrm{al}^{16}$ developed a new screening instrument, the Newest Vital Sign (NVS), to assess level of health literacy. Taking just 3 minutes to administer, the NVS assesses math, reading, and comprehension skills as well as abstract reasoning. Most importantly, its sensitivity was as great as the TOFHLA's for identifying those with inadequate health literacy. ${ }^{16}$ Initial testing was conducted on a small sample from university-affiliated primary care practices with few male patients $(8 \%)$. These populations may not represent most primary care offices. ${ }^{17}$

The purpose of this study was to determine the acceptability and timeliness of using the NVS to measure health literacy in various suburban, urban, and rural primary care settings. A secondary purpose was to determine the influence of taking a health class on one's level of health literacy.

\section{Methods}

St. John Hospital Institutional Review Board approved this cross-sectional study. The principal investigator (LCS) or a trained research assistant recruited participants. Demographic informationincluding the patient's stated age, gender, height, weight, smoking status, highest level of education, perceived health status, and whether the patient had ever taken a health class-was collected first. The NVS was then administered (see Figure 1). The NVS uses an ice cream nutrition label that the patient holds and reviews; then, 6 questions based on that nutrition label are given orally. Four or more correct answers indicate adequate literacy; 2 to 3 correct answers indicate limited literacy is possible, and 0 to 1 correct answers indicate limited health literacy is likely.

The NVS was administered to approximately 200 patients at each of 5 primary care sites: 2 suburban family medicine clinics, a rural family medicine clinic, an urban community health clinic, and during preparticipation sports physicals among middle- and high-school athletes in suburban areas. Fifty participants were timed as they were given the test, and all refusals were logged throughout the study at all sites. Any patient $\geq 13$ years of age was eligible for inclusion. Exclusion criteria included any individuals with organic brain disease or mental handicap, patients younger than 13 years, those unable to read English, and patients unable to see the nutrition label. At the 4 clinical sites, qualified, agreeing participants were tested one-on-one in a private setting before being seen by the physician.

\section{Statistical Analysis}

The $\chi^{2}$ test was used to compare rates of adequate health literacy for gender, educational level, smoking status, body mass index (BMI) classification, ethnicity, age (by decade), perceived health status, and whether individuals had taken a health class. Analysis of variance (ANOVA) compared age and BMI by literacy level. Logistic regression was also used to find predictors of health literacy (adequate or not adequate). $P<.05$ was considered significant. 
Figure 1. Tester verbally administers the questions on the left. The patient holds and uses the ice cream nutrition label on right to answer 6 questions. (NVS screening tool originally printed by Weiss, et al ${ }^{16}$ in 2005.) Reprinted with permission from "Quick Assessment of Literacy in Primary Care: The Newest Vital Sign," November/December 2005, Annals of Family Medicine. Copyright @ 2005 American Academy of Family Physicians. All Rights Reserved.

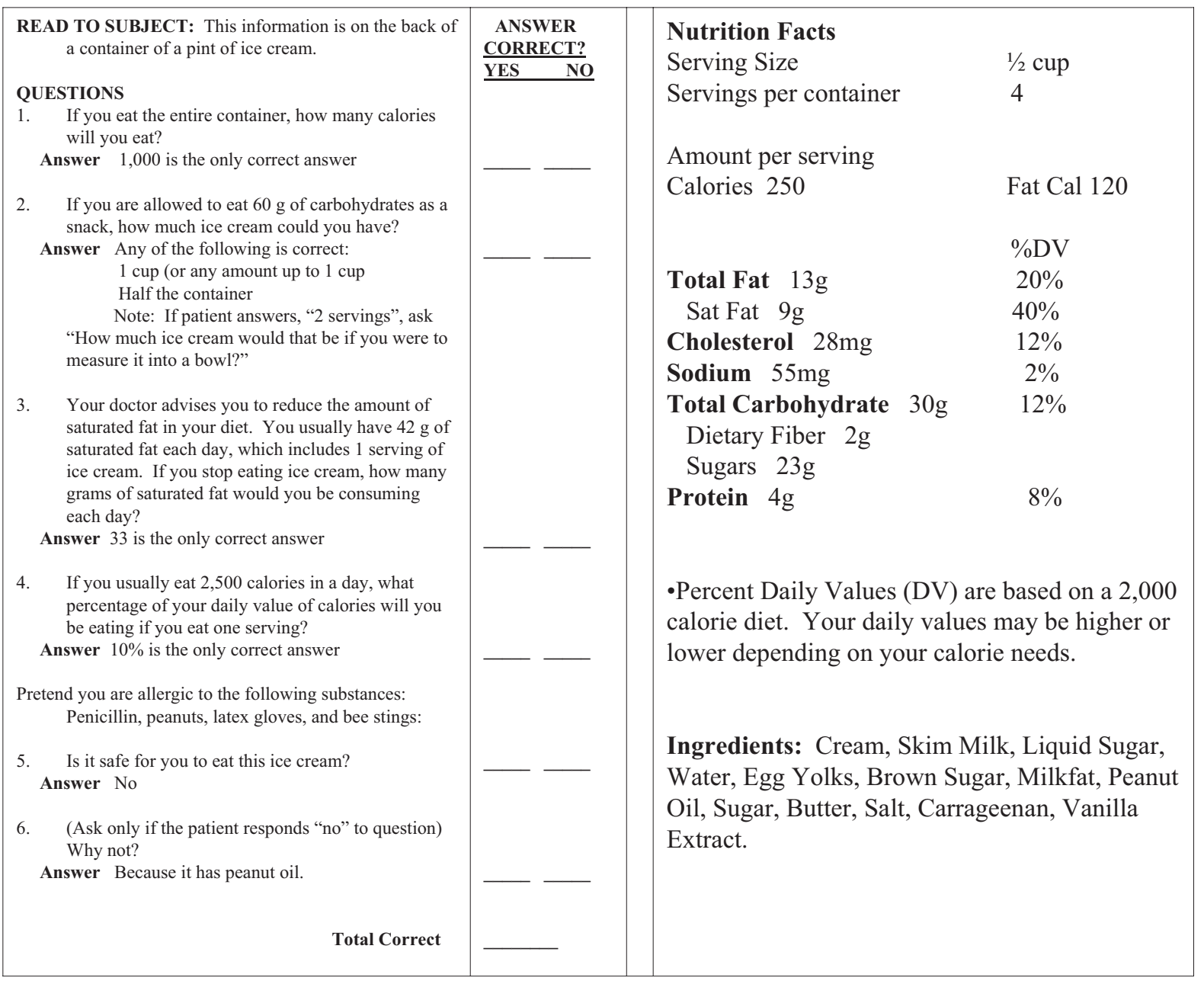

\section{Results}

A total of 1014 participants were equally distributed between the 5 sites. Only 29 individuals declined (response rate, $97.5 \%$ ). The average time to administer the test was just 2.6 minutes.

We detected differences between the middleand high-school athletes and the adults evaluated at clinics and found an interaction between race and gender; therefore, results are presented for each group. The mean age $( \pm \mathrm{SD})$ of adult participants $(\mathrm{n}=808)$ was $44.9 \pm 15.0$ years (range, 18 to 91$)$; men comprised $34.2 \%$ of the group $(n=274)$. Educational distribution revealed that most adults were high school graduates or had at least some college $(88.8 \%)$. Whites were the most represented race $(68.8 \%)$, followed by African Americans
(28.5\%), Hispanics (1.5\%), and other (1.2\%). The mean $\mathrm{BMI}( \pm \mathrm{SD}$ ) was $29.7 \pm 7.3$ (range, 12.9 to 62.8). Overall, inadequate health literacy was detected in $51.9 \%$ of adults.

The mean age $( \pm$ SD) of middle- and highschool athletes $(\mathrm{n}=206)$ at preparticipation health physicals was $15.0 \pm 1.3$ years (range, 13 to 20); boys comprised $53.4 \%$ of the group. Whites were the most represented race (90.8\%). The mean BMI was $22.3 \pm 3.8$ (range, 15.6 to 37.4 ). Overall, inadequate health literacy was detected in just $40.3 \%$ of these athletes.

As shown in Table 1, more women than men had adequate literacy, regardless of race, with white women the most likely to have adequate literacy and non-white men the least likely to have adequate 


\begin{tabular}{|c|c|c|}
\hline \multirow[b]{2}{*}{ Variable } & \multicolumn{2}{|c|}{ Adequate Literacy (\%) } \\
\hline & $\begin{array}{c}\text { Adult } \\
(\mathrm{n}=808)\end{array}$ & $\begin{array}{l}\text { Athletes }^{\ddagger} \\
(\mathrm{n}=206)\end{array}$ \\
\hline \multicolumn{3}{|l|}{ Gender $\times$ race $^{\dagger}$} \\
\hline White female & $63.2(222 / 351)$ & $65.5(57 / 87)$ \\
\hline White male & $47.5(95 / 200)$ & $61.0(61 / 100)$ \\
\hline Non-white female & $30.1(53 / 176)$ & $44.4(4 / 9)$ \\
\hline Non-white male & $23.0(17 / 74)$ & $10.0(1 / 16)$ \\
\hline \multicolumn{3}{|l|}{ Smoking status } \\
\hline Current smoker or quit $<5$ years ago & 44.8 & $62.5(5 / 8)$ \\
\hline Never smoked or quit $>5$ years ago & 50.4 & $59.6(118 / 198)$ \\
\hline \multicolumn{3}{|l|}{ Education level } \\
\hline$\leq 11$ th grade & 16.7 & 100 \\
\hline High school graduate or GED & 34.4 & \\
\hline Some college & 54.9 & \\
\hline College graduate; may have done postgraduate work & 77.5 & \\
\hline \multicolumn{3}{|l|}{ Self-reported health status } \\
\hline Fair or poor & 32.3 & 0.0 \\
\hline Good & 58.1 & 65.6 \\
\hline Excellent or very good & 57.0 & 59.3 \\
\hline Taken a health class & 55.0 & 57.3 \\
\hline
\end{tabular}

*Adequate refers to an Newest Vital Sign score of 3 to 6.

${ }^{\dagger}$ Includes African American (23.4\%), American Indian (1\%), Asian (0.3\%), and multiracial (0.5\%)

${ }^{\ddagger}$ Includes middle-school and high-school students who were approached at preparticipation sports physicals.

health literacy. For the rest of the variables in Table 1, only adults showed differences. More adults who never smoked or quit $>5$ years ago had adequate literacy than those who did not, and health literacy increased with education. Self-re- ported health status was rated as excellent or very good by $39.9 \%$ of those with adequate literacy whereas only $27.8 \%$ of adults with less-than-adequate literacy rated their health this highly. A fair or poor self-rating was given by just $15.9 \%$ of those

Figure 2. Health literacy decreases with age. Age by decades is plotted against adequate health literacy. The youngest participant was 13; the oldest was 91 . There was a significant effect of age category on health literacy $\left(\chi^{2}\right.$ $P<.0005)$. Total number of patients in each age bracket is shown within each bar.

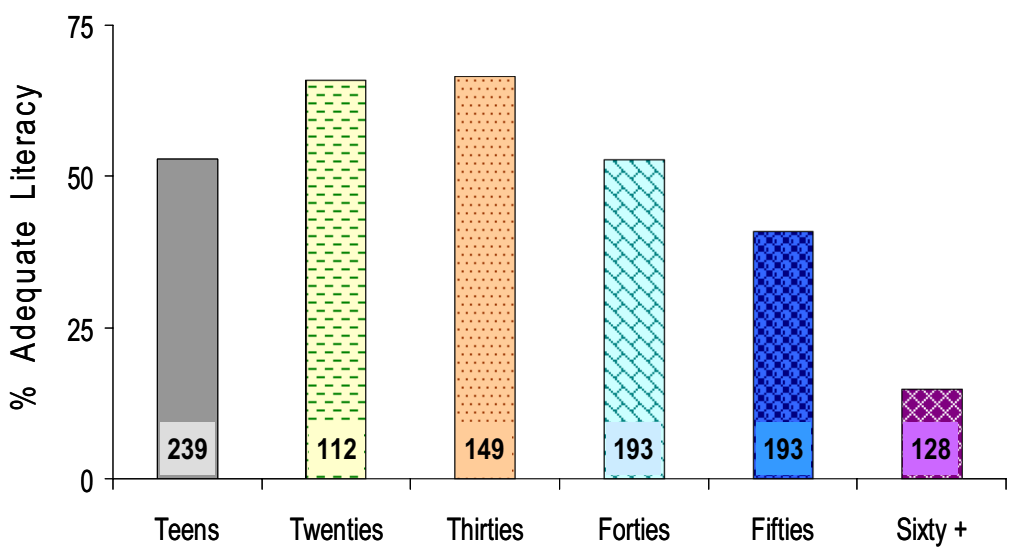

Age by Decades 
Figure 3. A higher percentage (55\%) of adults having adequate health literacy had taken a health class in school (left; $n=800 ; \chi^{2} P<.0005$ ), but this relationship was not true for teens still in school (right; $n=206 ; P=$ .485 ). Having taken a health class in school was a predictor in the logistic regression analysis for adults but not for teens. NVS, Newest Vital Sign.

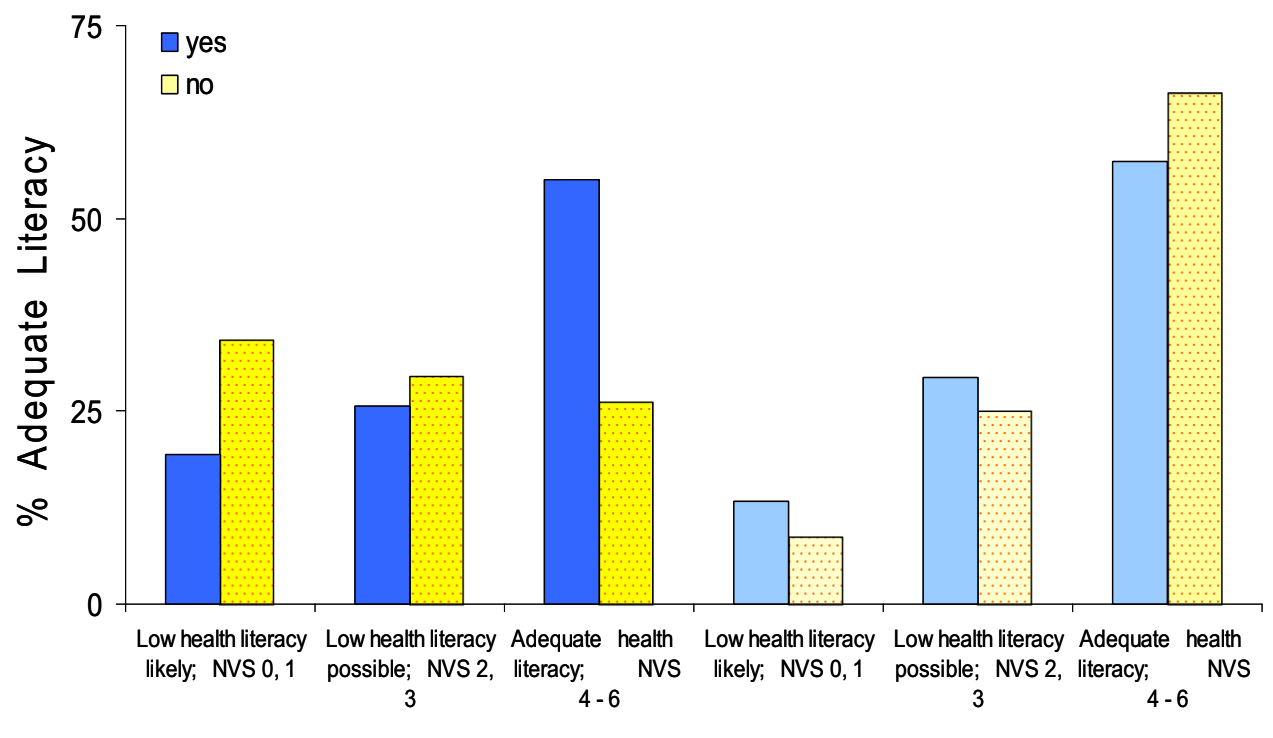

Adults

Teens

with adequate literacy, but $31.1 \%$ of those with less-than-adequate literacy chose this category.

As shown in Figure 2, health literacy decreased with advancing decades $(P<.0005)$. The mean age $( \pm \mathrm{SD})$ of adults likely to have low health literacy was $53.3 \pm 15.2$ years; of those with possible low health literacy, $45.9 \pm 15.4$ years; and of those with adequate health literacy, $40.0 \pm 12.5$ years (ANOVA; $P<.0005$ ).

Just more than half of adults (55.1\%) and middle- and high-school students (57.3\%) had taken a health class. A higher percentage of adequate health literacy $(55.1 \%)$ was observed for the adults who had taken a health class in school than for those who had not $(36.3 \%)\left(\chi^{2} ; P<.0005\right.$; see Figure 3). BMI for adults likely to have low health literacy was $29.9 \pm 7.8 \mathrm{~kg} / \mathrm{m}^{2}$; BMI for those adults with possible low health literacy was $29.7 \pm 7.2$ $\mathrm{kg} / \mathrm{m}^{2}$ and $29.5 \pm 7.3 \mathrm{~kg} / \mathrm{m}^{2}$ for those with adequate health literacy (ANOVA; $P=.871$ ). The proportion of adults demonstrating adequate health literacy in each of the 6 World Health Organization BMI categories did not differ $\left(\chi^{2} ; P=\right.$ $.509)$; this is plotted for adults and high-school athletes in Figure 4.
From the logistic regression, significant predictors of adequate health literacy are shown in Table 2, with odds ratio and $95 \%$ CI values reported for adults and middle- and high-school athletes. For both age groups, the significant negative predictor of health literacy was gender $\times$ race and the positive predictor was BMI. For adults, positive predictors additionally included more advanced education, younger age, and participation in a health class. We also examined which items of the NVS were most often answered correctly. Table 3 shows the percentage correct for each of the 6 NVS questions. The proportion of adults and teens correctly answering the question about calories in the entire ice cream carton (question 1) was not different; however, for every other question, young athletes scored better than adults. Interestingly, the most often missed items among adults and youth involved more complex mathematics (questions 3 and 4 , respectively).

\section{Discussion}

Our $51.9 \%$ adult inadequate health literacy rate is consistent with the 1993 and 2003 US Department of Education Adult Literacy Studies, ${ }^{18,19}$ which re- 
Figure 4. Body mass index, categorized using World Health Organization criteria, is depicted against adequate health literacy for adults (solid bars) and teens (dotted bars). There was no association of BMI with health literacy level among either group when evaluated by analysis of variance $(P>.05)$ or BMI category $\left(\chi^{2} P>.05\right)$. However, BMI category was the fourth of 5 predictors in the logistic regression analysis for adult participants (odds ratio, 1.040; 95\% CI, 1.016-1.065) and second of 2 predictors among teen athletes (odds ratio, 1.087; 95\% CI, 0.999-1.182). The number within each bar represents the number of patients with adequate literacy per group. No teen athlete fell in the Obesity II or Extreme Obesity BMI categories.

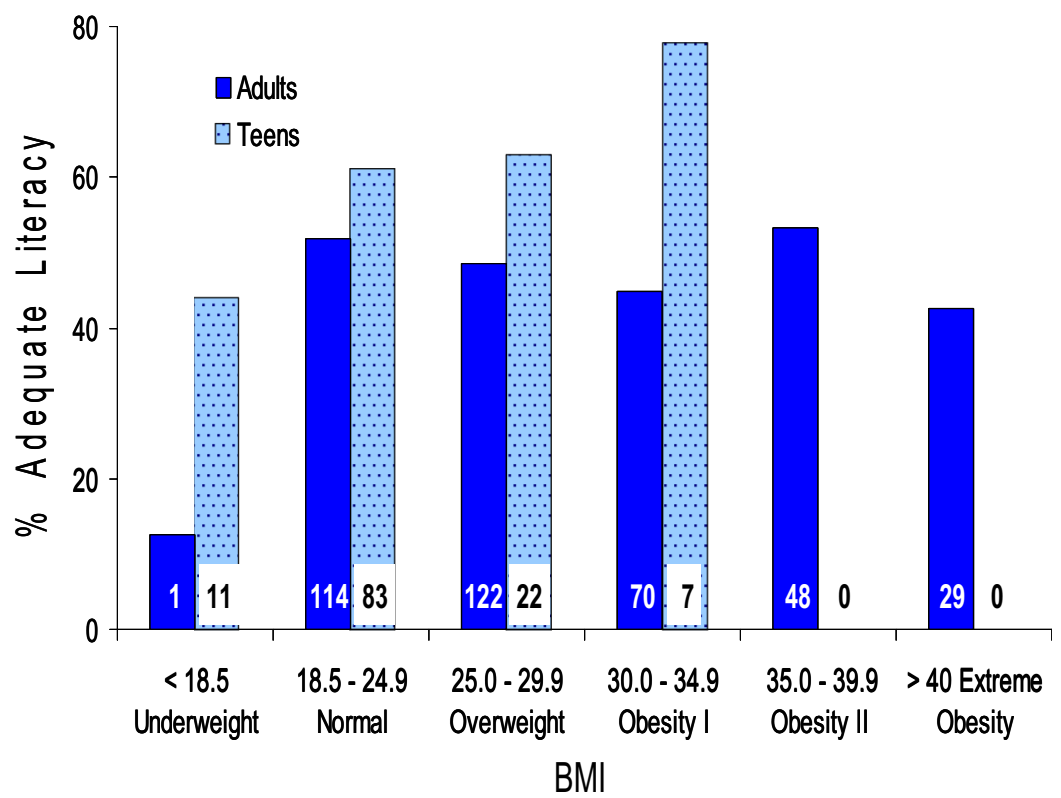

ported $34 \%$ to $51 \%$ of American adults had low levels of health literacy. The findings from our sample, the participants whom were evaluated with the NVS, also agreed with those first described by the NVS creators ${ }^{16}$ and with results using the
TOFHLA. ${ }^{9}$ That health literacy decreases with advancing age (Figure $2 ; \chi 2 ; P<.0005$; advancing age was the second strongest variable entered in the logistic regression) has been reported in several studies.,11,20-24 Among the elderly, deficits in

Table 2. Variables Predicting Adequate Health Literacy in Logistic Regression Analysis

\begin{tabular}{lcc}
\hline Predictor Variable & Adult $(\mathrm{n}=778)$ & MS and HS Athletes $(\mathrm{n}=206)$ \\
\hline Gender $\times$ race* & & 1 \\
White female & 1 & $0.713(0.384-1.324)$ \\
White male & $0.497(0.328-0.753)$ & $0.295(0.068-1.269)$ \\
Non-white female & $0.177(0.111-0.282)$ & $0.045(0.005-0.381)$ \\
Non-white male & $0.210(0.110-0.398)$ & - \\
Age & $0.953(0.941-0.965)$ & - \\
Education level & & 1 \\
11th grade or less & $1.80(0.909-3.565)$ & $1.087(0.999-1.182)$ \\
High school graduate or GED & $3.667(1.869-7.195)$ & - \\
Some college & $12.019(5.650-25.570)$ & - \\
College graduate; may have postgraduate work & $1.040(1.016-1.065)$ & $1.536(1.056-.235)$ \\
BMI & & \\
Taken a health class & & \\
\hline
\end{tabular}

Values provided as odds ratio (95\% CI). MS, middle school; HS, high school; BMI, body mass index.

*Includes African American (23.4\%), American Indian (1\%), Asian (0.3\%), and multiracial (0.5\%). 


\begin{tabular}{|c|c|c|c|}
\hline \multirow[b]{2}{*}{ Question No. } & \multirow[b]{2}{*}{ Abbreviated Question } & \multicolumn{2}{|c|}{ Percent Answering Correctly } \\
\hline & & $\begin{array}{c}\text { Adults } \\
(\mathrm{n}=778)\end{array}$ & $\begin{array}{l}\text { Young Athletes } \\
\quad(\mathrm{n}=206)\end{array}$ \\
\hline 1 & Calories in entire ice cream carton? & 54.5 & 52.9 \\
\hline 2 & How much ice cream has $60 \mathrm{~g}$ carbohydrates? & 56.9 & 66.0 \\
\hline 3 & Grams saturated fat in 1 serving? & 30.7 & 54.9 \\
\hline 4 & What \% of 2500 calorie daily intake is in this ice cream pint? & 39.7 & 48.5 \\
\hline 5 & If allergic to peanuts, can you eat this ice cream? & 71.8 & 82.0 \\
\hline 6 & If not, why not? & 61.4 & 77.7 \\
\hline
\end{tabular}

health literacy could occur as a result of declining cognitive function, increased time since formal education, and decreased sensory abilities., ${ }^{3,25,26}$ Clearly, health care providers need to make an extra effort with elderly patients to insure they understand the health information being conveyed.

Fewer years of formal education also was associated with less than adequate adult health literacy (Figure 3 and Table 2), a finding that is consistent across differing assessments. ${ }^{14,20-23,26-29}$ Although the association is strong, education should not be assumed to act as a surrogate for health literacy; in our study $37.6 \%$ of adults with at least some college education had limited literacy. In particular, a higher percentage of adequate health literacy was observed among the adults who had taken a health class, although this association was not seen among teens. Adults seemed to derive continuing benefit from their health class experience. Because teens are exercising their cognitive abilities daily and the NVS requires math skills for success, the benefit of a health class may have been obscured.

Gender/race was clearly associated with health literacy in our sample. More than $60 \%$ of white women had adequate health literacy whereas $<25 \%$ of non-white men were in that category (Table 1). Although a gender effect has been detected less often, ${ }^{23,25,28,30}$ race has been consistently reported to affect health literacy. ${ }^{20-22,24,28,29}$ It is possible that the effect of race is so strong in some studies that it swamped any effect of gender. It has been proposed that the lower health literacy rate among non-whites may be related to the underserved status of minority participants. ${ }^{31}$

Although BMI was not associated with health literacy in univariate analysis, BMI was the fourth of 5 variables entered into the logistic regression equation for adults and the second of 2 variables entered for middle- and high-school athletes (Fig- ure 4). In the majority of previous studies, no association was reported between BMI and health literacy. Having taken a health class was the last predictor variable for adults. The recognition of need for a functionally health literate population prompted the initiation of required health classes in school, ${ }^{32}$ and among our participants, this seemed to have a positive long-term effect (Figure 3 ). The decline in health literacy with age and time elapsed since formal education suggests that practitioners need to check for understanding more frequently as their patient population ages.

Self-reported health status has been shown to correlate with patient morbidity, and other researchers have described an association between health status and health literacy. ${ }^{20,28}$ Our patients' self-reported health status was significant in univariate but not multivariate analysis. It is probable that any influence of reported health status was absorbed by the age variable because health status declined with age (excellent or very good, age $31.8 \pm 18.0$ years; good, $42.8 \pm 16.6$ years, fair or poor, $46.8 \pm 14.6$ years; $P<.0005)$.

Few participants refused to take the NVS $(2.5 \%)$, which indicates that this tool is acceptable to patients. Previous studies found similar acceptability. ${ }^{33,34}$ The NVS was administered, on average, in less than 3 minutes, which demonstrates the utility of the NVS in primary care and which is consistent with prior findings. ${ }^{35}$ The NVS would not be administered during every patient visit, but our data suggest that periodic reassessment should prove helpful to target patient-provider communication appropriately.

\section{Limitations}

There were several limitations to this investigation. The entire sample was recruited from sites in southeastern Michigan, which may have limited the 
generalizability of our findings. It does, however, add to similar investigations that tested the NVS in other areas of the country. Secondly, the sample was recruited in health-related settings, so participants may be more familiar with health-related materials (including nutrition labels) than is the general public. Effort was made to recruit consecutive patients based on the availability of a research assistant. A small percentage of patients may have been missed, which leaves the possibility of selection bias. Lastly, a "gold standard" was not used to compare the NVS with a more tested instrument, but the original developers of the NVS have demonstrated good reliability with the S-TOFLHA. ${ }^{15}$

\section{Conclusion}

Our results underline that health literacy is affected by many factors including age, education, race, gender, and, among adults, taking a health education class. ${ }^{1}$ The NVS is an accurate, objective, easy-to-administer, and well-accepted measure that estimates health literacy in approximately $3 \mathrm{~min}$ utes. Time required to administer the NVS could be offset by the time saved on call-backs from patients and pharmacists because of poor understanding of diagnosis or medications. The NVS may also be particularly helpful for new patients with chronic medical conditions. Information obtained can help determine the appropriateness of patient education handouts and possibly the need for intensive patient education by ancillary staff. Future research about the effectiveness of intervention when inadequate health literacy is identified is the next logical step.

\section{References}

1. Berkman N, DeWalt D, Pignone M, et al. Literacy and health outcomes. Summary, evidence report/ technology assessment no. 87. Rockville, MD: Agency for Healthcare Research and Quality; 2004.

2. Wallace L, North American Primary Care Research Group. Patients' health literacy skills: the missing demographic variable in primary care research. Ann Fam Med 2006;4:85-6.

3. Davis TC, Long SW, Jackson RH, et al. Rapid estimate of adult literacy in medicine: a shortened screening instrument. Ann Fam Med 1993;25:391-5.

4. Sheridan SL, Harris RP, Woolf SH, for the SharedDecision Making Workground of the United States Preventative Task Force. Shared decision making about screening and chemoprevention, a suggested approach from the U.S. Preventative Services Task
Force. Rockville, MD: Agency for Healthcare Research and Quality; 2003.

5. Bass PF III, Wilson JF, Griffith CH, Barnett DR. Residents' ability to identify patients with poor literacy skills. Acad Med 2002;77:1039-41.

6. Rogers ES, Wallace LS, Weiss BD. Misperceptions of medical understanding in low-literacy patients: implications for cancer prevention. Cancer Control 2006;13:225-9.

7. Kelly PA, Haidet P. Physician overestimation of patient literacy: a potential source of health care disparities. Patient Educ Couns 2007;66:119-22.

8. US Department of Health and Human Services. Health communication. In: Healthy People 2010: Understanding and improving health and objectives for improving health, $2^{\text {nd }}$ ed. Washington, DC: US Government Printing Office; 2000.

9. Parker RM, Baker DW, Williams MV, et al. The test of functional health literacy in adults: a new instrument for measuring patients' literacy skills. J Gen Intern Med 1995;10:537-41.

10. Hawthorne G. Preteenage drug use in Australia: the key predictors and school-based drug education. J Adolesc Health 1996;20:384-95.

11. Schillinger D, Grumbach K, Piette J, et al. Association of health literacy and diabetes outcomes. JAMA 2002;288:475-82.

12. William MV, Baker DW, Parker RM, Nurrs JR. Relationship of functional health literacy to patients' knowledge of their chronic disease: a study of patients with hypertension and diabetes. Arch Intern Med 1998;158:166-72.

13. Osborn CY, Weiss BD, Davis TC, et al. Measuring adult literacy in health care: performance of the newest vital sign. Am J Health Behav 2007;31(Suppl 3):S36-S46.

14. Kim S, Love F, Quistber DA, Shea JA. Association of health literacy with self-management behavior in patients with diabetes. Diabetes Care 2004;27:2980-2.

15. Kann L, Telljohann SK, Wooley SF. Health education: results from the School Health Policies and Programs Study 2006. J Sch Health 2007;77:408-34.

16. Weiss BD, Mays MZ, Martz W, et al. Quick assessment of literacy in primary care: the Newest Vital Sign. Ann Fam Med 2005;3:514-22.

17. Middleton K, Hing E, Xu J. National Hospital Ambulatory Medical Care Survey: 2005 outpatient department summary. Adv Data 2007;(389):1-34.

18. Kirsch I, Jungeblut A, Jenkins L, Kolstad A. Adult literacy in America. A first look at the results of the national adult literacy survey. Washington, $\mathrm{DC}$ : National Center for Education Statistics, US Department of Education; 1993.

19. Kutner M, Greenberg E, Jin Y, Paulsen C. The health literacy of America's adults. Results from the 2003 national assessment of adult literacy. Washington, DC: National Center for Education Statistics, US Department of Education; 2006. 
20. Baker DW, Gazmararian JA, Williams MV, et al. Functional health literacy and the risk of hospital admission among Medicare managed care enrollees. Am J Public Health 2002;92:1278-83.

21. Davis TC, Wolf MS, Bass PF III, et al. Literacy and misunderstanding prescription drug labels. Ann Intern Med 2006;145:887-94.

22. Levinthal BR, Morrow DG, Tu W, Wu J, Murray MD. Cognition and health literacy in patients with hypertension. J Gen Intern Med 2008;23:1172-6.

23. Shea JA, Beers BB, McDonald VJ, Quistberg DA, Ravenell KL, Asch DA. Assessing health literacy in African American and Caucasian adults: disparities in rapid estimate of adult literacy in medicine (REALM) scores. Fam Med 2004;36:575-81.

24. Wolf MS, Gazmararian JA, Baker DW. Health literacy and functional health status among older adults. Arch Intern Med 2005;165:1946-52.

25. Benson JG, Forman WB. Comprehension of written health care information in an affluent geriatric retirement community: use of the Test of Functional Health Literacy. Gerontology 2002;48:93-7.

26. Downey LV, Zun LS. Assessing adult health literacy in urban healthcare settings. J Natl Med Assoc 2008; 100:1204-8.

27. Fredrickson DD, Washington RL, Pham N, Jackson T, Wiltshire J, Jecha LD. Reading grade levels and health behaviors of parents at child clinics. Kans Med 1995;96:127-9.
28. Morrow D, Clark D, Tu W, et al. Correlates of health literacy in patients with chronic health failure. Gerontologist 2006;46:669-76.

29. Echt KV, Schuchard RA, Schroeder DG. Characterizing older adults with high and low health literacy. Invest Ophthlmol Vis Sci 2002;43:E-abstract 3827.

30. Aguirre AC, Ebrahim N, Shea JA. Performance of English and Spanish S-TOFLA among publicly insured Medicaid and Medicare patients. Patient Educ Couns 2005;56:332-9.

31. Kickbusch IS. Health literacy: addressing the health and education divide. Health Promot Int 2001;16: 289-97.

32. Michigan Department of Education, Educational Materials Center. Content standards. Available at: http:// www.emc.cmich.edu/cshp/hesb.htm. Accessed 7 January 2009.

33. Ryan JG, Leguen F, Weiss BD, et al. Will patients agree to have their literacy skills assessed in clinical practice? Health Educ Res 2007;23:603-11.

34. Wolf MS, Williams MV, Parke RM, Parikh NS, Nowlan AW, Baker DW. Patients' shame and attitudes toward discussing the results of literacy screening. J Health Commun 2007;12:721-32.

35. Johnson K, Weiss BD. How long does it take to assess literacy skills in clinical practice? J Am Board Fam Med 2008;21:211-4. 